complicated and interesting picture.

As feared, secrecy (measured as unwillingness to discuss ongoing research with those outside the research group) has increased.

In 1966 (ref. 4), 50\% of 1,042 respondents reported feeling safe in talking with all others about their current research, but by 1998, when we surveyed 202 scientists from the same three fields (details of methods and results available from J.W.), the equivalent number was $26 \%$. Experimental biologists have become particularly secretive, with only $14 \%$ willing to talk openly about their current research in 1998. Secrecy is strongly predicted by scientific competition (measured as concern over having one's research results anticipated). The effects of commercial activity, on the other hand, are quite mixed. Patenting has no effect; industry funding is associated with greater secrecy; but having industry collaborators is associated with less secrecy.

These university-industry collaborations can be viewed as part of a strategy to share findings and expertise with the wider scientific and technical community. For companies, timeliness and customization of information are often more important than exclusivity, so they are willing to tolerate, even encourage, their academic collaborators' participation in the shared conversation of a scientific field, thereby giving the company access to the whole community's expertise. In contrast to these collaborations, industry funding alone is often associated with a university laboratory acting as a subcontractor to a company's R\&D project, and may produce associated secretive behaviour.

Thus, there is reason to believe that secrecy has increased among academic scientists, but that the focus on commercialization as the cause may be misplaced. Although commercial activity may reduce formal activities such as publication or sharing of materials, it may have fewer negative effects on informal communication among researchers. As this informal communication is significant in transferring information to companies ${ }^{5}$ and is at least as important as publication for distributing information among scientists, this is encouraging news.

Although it is right to raise concerns about the negative effects of publication restrictions associated with industry funding, we should not conclude that university-industry linkages per se produce unhealthy levels of secretiveness among academic scientists. Instead, it may be better to focus on alleviating some of the negative consequences of scientific competition.
Recent increases in US government funding for science, if they are sustained, may help to lower the intensity of competition, as well as the dependence on industry funding, and thereby reduce secrecy. Furthermore, although we need to be wary of the strings attached to industry funding, university-industry collaborative research should be encouraged.

We thank Lowell Hargens for providing field-level data from ref. 4.

John P. Walsh ${ }^{\star} \dagger$, Wei Hong $\dagger$

${ }^{*}$ Research Center for Advanced Economic

Engineering, University of Tokyo, 4-6-1 Komaba,

Meguro-ku, Tokyo 153-8904, Japan

walsh@aee.u-tokyo.ac.jp.

$\dagger$ Department of Sociology, University of Illinois,

Chicago, Illinois 60607-7140 USA

1. Blumenthal, D. et al. J. Am. Med. Assoc. 277, 1224-1228 (1997).

2. Cook-Deegan, R. M. \& McCormack, S. J. Science 293, 217 (2001).

3. Campbell, E. G. et al. J. Am. Med. Assoc. 287, 473-480 (2002).

4. Hagstrom, W. O. Am. Sociol. Rev. 39, 1-18 (1974).

5. Cohen, W. M., Nelson, R. R. \& Walsh, J. P. Management Sci. 48, 1-23 (2002).

\section{Pre-genomics training hinders Indian biotech}

Sir - Ashok Parthasarathi in his

Commentary "India: a champion of new technologies" (ref. 1) rightly affirms India's bid to play a leading part in global technology developments. India's technological independence has come mainly in the physical sciences, such as space research, telecommunications, software, defence systems, energy and supercomputing.

Although Parthasarathi lists biotechnology as a key 'champion technology', a tremendous boost is needed for it to make a global impact.

India shares this predicament with other developing countries that have a vast research force but the training and infrastructure of pre-genomics days, and little experience of the research skills required for post-genomic biology. With the genome sequence data for several organisms, including humans, now available, the rules of knowledgebased commercial ventures have changed and an era of 'omics' - genomics, proteomics and so on - has emerged ${ }^{2}$, with functional genomics as the new 'mantra'.

In order to become a champion of biotechnology, India needs a paradigm shift in the organization of research and training, priming research institutions and universities to change gear and meet global challenges. Two aspects need urgent attention: establishing functionalgenomics centres for biotechnology and related basic science research, as is done in $\mathrm{China}^{3}$; and training researchers in state-of-the-art skills, along the lines of initiatives by the European Molecular Biology Laboratory.

All the stakeholders - in the fields of policy, administration, science and industry - have to address this problem and give a directional nudge to research initiatives.

Nature has covered some of these issues recently, for example the low impact factors of Indian biological-science journals ${ }^{4}$; the urgent need to explore the best scientific options for sustainable development by regional centres of the International Council of Science ${ }^{5}$; and the effect of post-genomics research on traditional methods of food production ${ }^{6}$. Informal articles on topics such as these serve as a compass for framing policies and making course corrections during implementation.

\section{R. M. Ranganath}

Department of Botany, Bangalore University, Jnanabharathi Campus,

Bangalore 560056, India

1. Parthasarathi, A. Nature 422, 17-18 (2003).

2. Palsson, B. Nature Biotechnol. 20, 649-650 (2002).

3. Cyranoski, D. Nature 410, 10-12 (2001).

4. Vohora, S. B. \& Vohora, D. Nature 412, 583 (2001).

5. Clarke, T. Nature 420, 733 (2002).

6. Knight, J. Nature 421, 568-570 (2003).

\section{Should tobacco ban rule out governments too?}

Sir - I was interested to read in your News story "Academics fume as university refuses to reject tobacco dollars" (Nature 422, 361; 2003) a scientist at the University of California, San Francisco, quoted as saying it is immoral to accept research funds from tobacco companies because "it is not appropriate to take money from an industry that kills 5 million people worldwide and constantly lies".

I guess that means that no research funds should be accepted from the US Department of Defense, nor from its corporate headquarters - the US government. Other national governments would presumably also be banned from supporting research under these new politically correct guidelines.

\section{Richard S. Jope}

Department of Psychiatry,

Sparks Center 1057, 17207 th Avenue South,

University of Alabama at Birmingham,

Birmingham, Alabama 35294-0017, USA

\section{correspondence}

Contributions to Correspondence may be submitted to corres@nature.com. They should be no longer than 500 words, and ideally shorter. Published contributions are edited. 